\title{
Absorção de IgG via colostro em leitões biológicos e adotados após a uniformização da leitegada
}

\author{
[Absorption of IgG via colostrum in biological piglets and adopted piglets after crossfostering] \\ G. Heim ${ }^{1}$, A.P.G. Mellagi ${ }^{1}$, T. Bierhals ${ }^{1}$, P. Piuco ${ }^{1}$, L.P. Souza ${ }^{1}$, D. Gava ${ }^{1}$, C.W. Canal ${ }^{2}$, \\ M.L. Bernardi ${ }^{3}$, I. Wentz ${ }^{1}$, F.P. Bortolozzo ${ }^{1 *}$ \\ ${ }^{1}$ Setor de Suínos, Faculdade de Veterinária - UFRGS - Porto Alegre, RS \\ ${ }^{2}$ Laboratório de Virologia, Faculdade de Veterinária - UFRGS - Porto Alegre, RS \\ ${ }^{3}$ Departamento de Zootecnia, Faculdade de Agronomia - UFRGS - Porto Alegre, RS
}

\section{RESUMO}

Nove fêmeas de quinto parto (OP5) foram imunizadas com 4mg e 2mg de albumina sérica bovina (BSA) aos

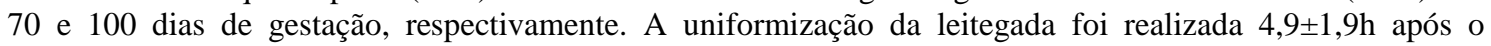
nascimento, antes de os leitões efetuarem a primeira mamada. As leitegadas foram compostas por cinco leitões biológicos (LB) e cinco leitões adotados (LA), com pesos semelhantes ao nascimento. Foram coletadas amostras de sangue dos leitões ao nascimento e 24h após, das fêmeas ao pós-parto e de colostro de cada grupo de tetos ao parto e $24 \mathrm{~h}$ após. As amostras de soro e colostro foram quantificadas para IgG pelo ELISA indireto. A densidade ótica de IgG anti-BSA (DOIgG-BSA) dos leitões (24h de vida) foi correlacionada com a das fêmeas. A DOIgG-BSA entre LB e LA foi semelhante, assim como entre os grupos de tetos, ao parto e 24h após. Entretanto, ocorreu redução na DOIgG-BSA do parto até 24h após. LB e LA absorveram a mesma quantidade de IgG via colostro, quando a uniformização foi realizada até 5h pós-parto, independentemente do teto em que os leitões mamaram, uma vez que esses possuem a mesma concentração de IgG.

Palavras-chave: leitão, uniformização, IgG, colostro

\begin{abstract}
Nine sows of fifth parity (PO5) were immunized with $4 \mathrm{mg}$ and $2 \mathrm{mg}$ of bovine serum albumin (BSA) at 70 and $100 d$ of gestation, respectively. Cross fostering was performed $4.9 \pm 1.9 \mathrm{~h}$ after birth, before piglets had their first suckling. Litters were composed of five biological piglets (BP) and five adopted piglets (AP), with similar weight at birth. Blood samples were collected from piglets (at birth and at $24 \mathrm{~h}$ of life) and from females (after farrowing) and colostrum from each group of teats (at farrowing time and after 24h). Samples of serum and colostrum were quantified to IgG by indirect ELISA. Optical density of IgG anti-BSA (ODIgG-BSA) from piglets (24h of life) was correlated with dams. ODIgG-BSA was similar among BP and AP, as well as among pairs of teats (at farrowing time and after 24h). However, there was a decrease in ODIgG-BSA from farrowing up to $24 \mathrm{~h}$ after birth. BP and AP absorbed the same amount of IgG via colostrum, when cross fostering was evaluated $5 \mathrm{~h}$ after farrowing, regardless of the teat suckled, since these have the same concentration of IgG.
\end{abstract}

Keywords: piglet, crossfostering, IgG, colostrum

\section{INTRODUÇÃO}

Uniformização de leitegadas é a transferência de leitões de leitegadas mais numerosas para as menos numerosas, ou é a formação de leitegadas com leitões de pesos semelhantes ao nascimento (Straw et al., 1998; Robert e Martineau,

Recebido em 16 de julho de 2010

Aceito em 1 de julho de 2011

*Autor para correspondência (corresponding author)

E-mail: fpbortol@ufrgs.br
2001). Essa prática deve ser realizada, preferencialmente, entre seis e 24 horas após o parto, período em que ainda não houve a definição da ordem de tetos de toda a leitegada que geralmente ocorre em até 36-48 horas -, e para que os leitões absorvam o máximo de imunoglobulinas (Igs) do colostro de sua mãe biológica (Straw et al., 1998; Robert e Martineau, 2001; Pieters et al., 2008). 
É comum os leitões adotados passarem de duas a seis horas após a uniformização vocalizando e errantes pela baia de parição, perdendo algumas mamadas (Straw et al., 1998; Robert e Martineau, 2001), o que pode prejudicar a ingestão de colostro. Os leitões dependem do colostro para aquisição de Igs (IgG, IgM, IgA) e linfócitos (Nechvatalova et al., 2011), uma vez que a placenta dos suínos é do tipo epiteliocorial difusa, ou seja, não há transferência dessas para os conceptos (Bourne et al., 1978; Stokes e Bourne, 1989). As Igs são importantes para a sobrevivência e proteção inicial dos leitões frente aos diferentes agentes infecciosos (Blecha et al., 1983; Wagstrom et al., 2000). Eles, portanto, nascem praticamente sem proteção contra os patógenos existentes no ambiente, e conseguem desenvolver suas próprias respostas humorais ou celulares contra antígenos em sete a 10 dias após o contato com os agentes infecciosos (Klobasa et al., 1981; Salmon, 1999).

Após o parto, a concentração de Igs, principalmente IgG, no colostro, diminui a cada mamada sucessiva. A absorção máxima das Igs pelas células epiteliais dos intestinos do leitão neonato ocorre nas primeiras 12 horas após o nascimento e diminui bruscamente em 24 a 36 horas (Klobasa et al., 1987; Machado Neto et al., 1987; Rooke et al., 2003). Quanto mais próximo ao nascimento o leitão mamar, mais cedo ele estará protegido contra os diferentes patógenos, e quanto maior for o período entre o nascimento e a primeira mamada, maior será a chance de estabelecer uma infecção. A ingestão adequada de colostro é garantida quando os leitões começam a mamar já na primeira hora após o nascimento (Morés et al., 1998).

Com o aumento no tamanho da leitegada ocorrido nos últimos anos e consequente aumento na duração do parto, surgiram novos desafios com o tradicional manejo empregado na uniformização das leitegadas. Em razão da maior duração do parto, em muitas ocasiões a uniformização da leitegada inicia-se antes do término do parto, o que pode limitar o desenvolvimento imunológico dos animais, uma vez que linfócitos do colostro são transferidos para o neonato apenas pelo colostro da mãe biológica (Williams, 1993). Além disso, leitegadas maiores estão associadas ao aumento na variação individual do peso ao nascer dos leitões, fato que tende a intensificar o número de leitões transferidos, pois ainda não se sabe se os leitões adotados teriam a mesma capacidade de absorção de Igs quando comparados aos leitões não adotados. Nesse contexto, o objetivo do estudo foi avaliar se a absorção de IgG, a principal Ig do colostro, é maior em leitões filhos biológicos do que em adotados, em casos em que a uniformização da leitegada é realizada antes de os leitões efetuarem sua primeira mamada.

\section{MATERIAL E MÉTODOS}

O experimento utilizou nove fêmeas de quinto parto (OP5), da genética Agroceres PIC $^{(}$, as quais foram imunizadas com duas doses $-2 \mathrm{~mL}$ na primeira dose e $1 \mathrm{~mL}$ na segunda dose - de albumina sérica bovina (BSA - A3912 Sigma Aldrich $^{\circledR}$ ) com adjuvante Marcol 52 (Esso ${ }^{\circledR}$ ) e Montanide 888 (Seppic ${ }^{\circledR}$ ), por via intramuscular, utilizando-se $4 \mathrm{mg}$ e $2 \mathrm{mg}$ de BSA (McKinnie et al., 1988), aos 70 e 100 dias de gestação, respectivamente.

Os partos foram induzidos por administração de 0,5mL (0,13mg) de cloprostenol sódico (Ciosin ${ }^{\circledR}$, Fort Dodge Saúde Animal, Campinas) via intramucosavulvar (IMV) aos 113 dias de gestação. Vinte e quatro horas após a indução, foi administrado, também por via IMV, $0,5 \mathrm{~mL}$ (5UI) de ocitocina (Orastina ${ }^{\circledR}$, Intervet International $\mathrm{GmbH}$, Unterschleissheim). Os partos foram acompanhados e os leitões foram separados da mãe por uma barreira física, a fim de impossibilitar a mamada do colostro até o momento da uniformização, a qual foi realizada, em média, 4,9 $\pm 1,9$ horas após o nascimento. A cada duas horas, do nascimento até a uniformização, foram administrados 500mg de glicose por via intraperitoneal nos leitões. No momento da uniformização, as leitegadas foram compostas por cinco leitões filhos biológicos (LB) e cinco leitões adotados (LA), com média de peso semelhante ao nascimento de 1487,0 $0232,4 \mathrm{~g}$ e $1571,3 \pm 203,1 \mathrm{~g}$, respectivamente $(\mathrm{P}>0,05)$.

As 20 primeiras mamadas, dos 90 leitões, foram avaliadas para definir o número de mamadas perdidas. Para a avaliação das mamadas, assim que os grupos foram formados, os leitões foram presos no escamoteador por 50 minutos. Após esse período, foram, então, liberados para a observação da mamada. A liberação do leite e da mamada propriamente dita foi caracterizada pelo 
momento em que os leitões mudaram os movimentos de sucção de lentos para rápidos e assim permaneceram por aproximadamente 15 segundos. Considerou-se como início da mamada o momento em que a metade dos leitões estava sugando os tetos e como fim, quando metade deles liberavam os tetos ou ficavam inativos, próximos ao úbere (Wattanakul et al., 1998). Uma mamada perdida foi considerada quando os eventos acima descritos não foram realizados. Após a liberação do leite, os leitões permaneceram soltos, em contato com a fêmea por 20 minutos e, então, foram novamente presos no escamoteador. Esse manejo, chamado 50X20, foi realizado 20 vezes. Os leitões foram identificados com número sequencial na região dorsal, para melhor visualização.

Foram coletadas amostras de sangue dos leitões, $3 \mathrm{~mL}$, ao nascimento e com $24 \mathrm{~h}$ de vida, bem como das fêmeas, $10 \mathrm{~mL}$, logo após o parto. As amostras de sangue foram obtidas pela punção na região do complexo jugular. Também foi coletado colostro de cada grupo de tetos, $3 \mathrm{~mL}$ : peitorais - primeiro e segundo pares de tetos -, abdominais - terceiro, quarto e quinto pares - e inguinais - sexto, sétimo e oitavo pares (Elmore e Martin, 1986), no parto e 24 horas após. Após retração do coágulo, as amostras de sangue foram centrifugadas a 3000rpm por 15 minutos para obtenção do soro, bem como as de colostro para separação e posterior remoção da gordura.

As amostras de soro e colostro foram quantificadas para IgG pelo ELISA indireto. As placas de 96 poços (Falcon 3912 ${ }^{\circledR}$ ) foram revestidas com $100 \mu \mathrm{L}$, por poço, de BSA, na concentração de $500 \mu \mathrm{g} / \mathrm{mL}$, em tampão carbonato de sódio $(0,2 \mathrm{M}$ e $\mathrm{pH} 9,2)$, e incubadas a $4^{\circ} \mathrm{C}$ overnight. Para controle positivo, foi utilizado soro de suíno hiperimune para BSA, e como controle negativo, soro de suíno SPF (specific-pathogen-free). Todas as amostras de soros foram testadas em duplicata, $100 \mu \mathrm{L} /$ poço, na diluição 1:15000, e incubadas por duas horas. Após, as placas foram incubadas com $100 \mu \mathrm{L}$ do soro anti-IgG de suíno conjugado com peroxidase (A5670 Sigma Aldrich ${ }^{\circledR}$ ) na diluição 1:5000, por 30 minutos, seguida da adição de $150 \mu \mathrm{L}$ de solução reveladora (OPD - P9029 Sigma-Aldrich $^{\circledR}$ ). Passados 15 minutos de incubação, a reação foi bloqueada com $50 \mu \mathrm{L} /$ poço de ácido sulfúrico (2M). A densidade ótica (DO) foi lida em espectrofotômetro com filtro de 495nm. Entre cada etapa, as placas foram lavadas três vezes com solução PBS Tween 20, e todas as incubações foram realizadas em câmara úmida a $37^{\circ} \mathrm{C}$.

Três leitões LB e dois leitões LA foram excluídos em razão da não obtenção de sangue. Os dados de DO e o número de mamadas perdidas foram analisados pelo procedimento NPAR1WAY (SAS), e a comparação entre os grupos de leitões ou pares de tetos foi efetuada com os testes de Wilcoxon e Kruskal-Wallis, respectivamente. A correlação entre a densidade ótica de IgG anti-BSA dos leitões e das fêmeas, nas 24 horas de vida, foi analisada pelo procedimeno CORR (SAS).

\section{RESULTADOS E DISCUSSÃO}

A densidade ótica de IgG anti-BSA do soro dos leitões antes de eles mamarem o colostro, hora zero, foi semelhante à do controle negativo, confirmando resultados já encontrados por outros autores, que afirmaram que não há transferência de Igs via placenta para os leitões (Bourne et al., 1978; Stokes e Bourne, 1989). Portanto, os leitões nascem, praticamente, agamaglobulinêmicos, ou seja, sem proteção contra patógenos existentes no novo ambiente (Salmon, 1999). Os conceptos têm baixa capacidade de produzir anticorpos pelo fato de não estarem expostos a agentes infecciosos durante a vida intrauterina (Klobasa et al., 1981). Logo, o colostro é a única fonte de anticorpos maternos para o recém-nascido, uma vez que os leitões que não receberem anticorpos passivos primários desenvolverão respostas imunes a antígenos após sete a 10 dias pós-parto (Klobasa et al., 1981; Salmon, 1999). Assim, leitões ao nascer dependem inteiramente do colostro para aquisição das Igs que irão conferir a proteção inicial, importante para sua sobrevivência (Wagstrom et al., 2000).

Nas 24 horas de vida, a densidade ótica de IgG anti-BSA dos leitões foi altamente correlacionada com a das fêmeas $(r=0,81$; $\mathrm{P}<0,05$ ), pois, quando o leitão ingere uma boa quantidade de colostro e no momento adequado, terá imunidade sérica comparável à da mãe, em natureza e especificidade (Rooke et al., 2003).

Não foi observada diferença na densidade ótica de IgG anti-BSA entre os leitões filhos biológicos e os adotados (Fig. 1), o que pode ser 
explicado pelo fato de que o número de mamadas perdidas, nas primeiras 24 horas, foi semelhante $(\mathrm{P}>0,05)$ entre os grupos, 2,2 vs. 3,3, respectivamente. $\mathrm{O}$ curto período entre $\mathrm{o}$ nascimento e a uniformização deve ter contribuído para que os leitões adotados não estranhassem tanto o novo ambiente e sua mãe adotiva. De acordo com Alonso-Spilsbury et al. (2007), leitões adotados distinguem seu ambiente e sua mãe adotiva em 12 a 24 horas após o nascimento. Segundo Heim et al. (2009), leitões adotados perdem maior percentual de mamadas em relação aos leitões biológicos, 34,5 $\pm 3,7 \%$ vs. $24,8 \pm 2,9 \%$, respectivamente, no dia da uniformização, que ocorre, em média, 20 horas após o parto. Nos demais dias, não houve diferença no percentual de mamadas perdidas. Também, o fato de os leitões adotados e os biológicos terem pesos semelhantes ao nascimento deve ter reduzido a disputa pelos tetos, visto que eles se distribuíram de maneira homogênea entre os pares de tetos.

Mesmo não havendo diferença na densidade ótica de IgG anti-BSA entre leitões biológicos e adotados, a uniformização deve ser realizada, preferencialmente, após seis a 12 horas do fim do parto, para que os leitões absorvam linfócitos colostrais e o máximo de Igs do colostro de sua mãe biológica (Pieters et al., 2008), e até 24 horas, momento em que a maioria dos leitões ainda não definiu sua teta (Robert e Martineau, 2001). Além disso, Tuboly et al. (1988) observaram que a absorção de células colostrais somente ocorre quando o leitão mama na mãe biológica, o que lhe confere imunidade celular. Existem situações em que a uniformização tem que ser realizada antes das seis horas do fim do parto, como, por exemplo, em casos de excesso de leitões. Entretanto, antes de serem transferidos, estes devem ingerir suficiente quantidade de colostro. Em situações em que não há fêmeas disponíveis para transferir os leitões em excesso, é aconselhado colocar os leitões maiores no escamoteador, por duas horas, enquanto os menores efetuam as primeiras mamadas (Wattanaphansak et al., 2002).

Não houve diferença na densidade ótica de IgG anti-BSA entre os pares de tetos, tanto no momento do parto como 24 horas após (Fig. 2). Em contraste, Inoue et al. (1980) e Bland e Rooke (1998) observaram tendência de os tetos inguinais terem menor concentração de IgG em relação aos demais tetos.

Foi observada redução $(\mathrm{P}<0,05)$ na densidade ótica de IgG anti-BSA das amostras de colostro do parto e de 24 horas após (Fig. 2), isto é, a concentração de IgG no colostro diminui a cada aleitamento (Klobasa et al., 1987; Machado Neto et al., 1987). De acordo com Foisnet et al. (2010), em seis horas após o início do parto há redução de $23 \%$ na concentração de IgG. Além da queda da concentração de IgG, a absorção através do epitélio intestinal do neonato ocorre por apenas algumas horas, desde o nascimento até 24-36 horas (Bourne et al., 1978; Machado Neto et al., 1987; Rooke et al., 2003), quando os enterócitos do intestino delgado cessam a transferência de macromoléculas intactas através da membrana basolateral, processo conhecido como "fechamento intestinal" (Smith e Jarvis, 1978). O mecanismo dos fatores que influenciam o fechamento não está completamente esclarecido, mas é reconhecido que os componentes do colostro aceleram este processo, como a concentração periparto de cortisol (Burton e Smith, 1977; Bate et al., 1991; Connell et al., 1995). Nesse período inicial, as células do epitélio intestinal neonatal são altamente vacuolizadas, imaturas e capazes de absorver macromoléculas, tais como as Igs (Werhahn et al., 1981). A absorção se dá por endocitose e subsequente movimento transcelular das macromoléculas em todo o epitélio intestinal (Burton e Smith, 1977). A IgA absorvida é ressecretada em superfícies mucosas do neonato, enquanto a IgG permanece na circulação (Stokes e Bourne, 1989). 


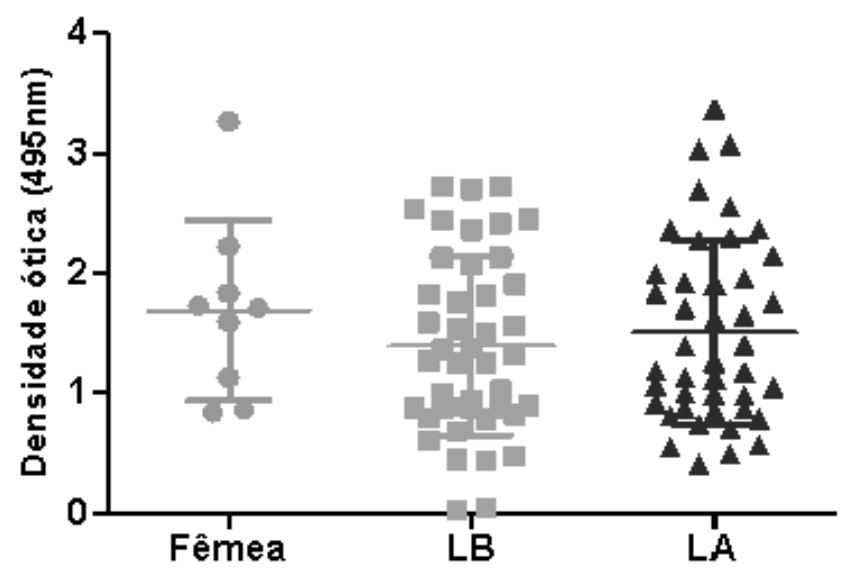

Figura 1. Densidade ótica de IgG anti-BSA no soro de fêmeas (no parto) e no soro de leitões biológicos (LB) ou adotados (LA) (24h após o nascimento). Não houve diferença na mediana entre os grupos LB e LA $(\mathrm{P}>0,05)$.

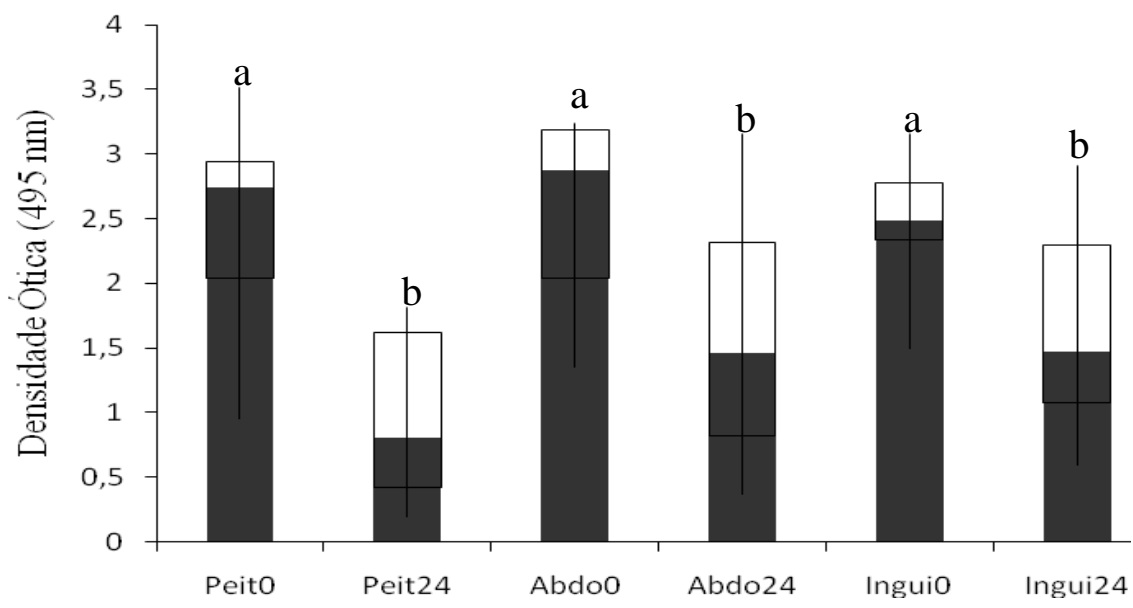

Figura 2. Densidade ótica de IgG anti-BSA no colostro de tetos peitorais (Peit), abdominais (Abdo) e inguinais (Ingui) no parto (0) e 24h após (24). Nas caixas são mostrados os valores de mínimo, primeiro quartil, terceiro quartil e máximo. O limite superior da barra cinza representa o valor da mediana. a, b indicam medianas diferentes $(\mathrm{P}<0,05)$.

\section{CONCLUSÕES}

Leitões filhos biológicos e adotados, de pesos semelhantes, perdem o mesmo número de mamadas e apresentam a mesma densidade ótica de IgG anti-BSA no soro nas primeiras 24 horas de vida, quando a uniformização é realizada até cinco horas após o parto, independentemente do par de tetos em que mamaram, uma vez que esses possuem a mesma densidade ótica de IgG anti-BSA.

\section{REFERÊNCIAS BIBLIOGRÁFICAS}

ALONSO-SPILSBURY, M.; RAMÍREZ-NECOECHEA, R.; GONZÁLEZ-LOZANO, M. et al. Piglets survival in early lactation: a review. J. Anim. Vet. Adv., v.6, p.76-86, 2007.

BATE, L.A.; IRELAND, W.; CONNELL, B.J. et al. Development of the small intestine of piglets in response to prenatal elevation of glucocorticoids. Histol. Histopathol., v.6, p.207-216, 1991.

BLAND, I.M.; ROOKE, J.A. Effects on colostrum immunoglobulin $\mathrm{G}$ (IgG) concentrations and piglet colostrum intake of sow, udder section and time. In: BRITISH SOCIETY OF ANIMAL SCIENCE, 1998, Scarborough, UK. Proceedings... Medlothian: British Society of Animal Science, 1998. p. 158. 
BLECHA, F.; POLLMANN, D.S.; NICHOLS, D.A Weaning pigs at an early age decrease cellular immunity. $J$. Anim. Sci., v.56, p.396-400, 1983.

BOURNE, F.J.; NEWBY, T.J.; EVANS, P. et al. The immune requirements of the newborn pig and calf. Ann. Rech. Vet., v.9, p.239-244, 1978.

BURTON, K.A.; SMITH, M.W. Endocytosis and immune globulin transport across the small intestine of the new-born pig. J. Physiol., v.270, p.473-488, 1977.

CONNELL, B.J.; BATE, L.A.; IRELAND, W. et al. Morphological changes in the small intestine of the fetal pig after prenatal stimulation of the sow with ACTH. Histol. Histopathol., v.10, p.255-264, 1995.

ELMORE, R.G.; MARTIN, C.E. Mammary glands. In: LEMAN, A.D.; STRAW, B.; GLOCK, R.D. et al. (Eds.) Diseases of Swine. Ames: Iowa State University, 1986. p.168-182.

FOISNET, A.; FARMER, C.; DAVID, C. et al. Relationships between colostrum production by primiparous sows and sow physiology around parturition. J. Anim. Sci., v.88, p.16721683, 2010.

HEIM, G.; MELLAGI, A.P.G.; BIERHALS, T. et al. Comportamento e peso de leitões filhos biológicos e adotados submetidos à uniformização da leitegada. In: CONGRESSO BRASILEIRO DE VETERINÁRIOS ESPECIALISTAS EM SUÍNOS (ABRAVES), 14., 2009, Uberlândia. Anais... Belo Horizonte: ABRAVES-MG, 2009. p.602-603.

INOUE, T.; KITANO, K.; INOUE, K. Possible factors influencing immunoglobulin $\mathrm{G}$ concentration in swine colostrum. Am. J. Vet. Res., v.42, p.533-536, 1980.

KLOBASA, F.; BUTLER, J.E. Absolute and relative concentration of immunoglobulins G, M, and A, and albumin in the lacteal secretion of sows of different lactation numbers. Am. J. Vet. Res., v. 48, p. 176-182, 1987.

KLOBASA, F.; WERHAHN, E.; BUTLER, J.E. Regulation of humoral immunity in the piglet by immunoglobulins of maternal origin. Res. Vet. Sci., v.31, p.195-206, 1981.

MACHADO NETO, R.; GRAVES, C.N.; CURTIS, S.E. Immunoglobulins in piglets from sows heat-stressed prepartum. J. Anim. Sci., v.65, p.445-455, 1987.

McKINNIE, M.R.; BRITT, J.H.; ESBENSHADE, K.L. Ovarian function and hormone secretion of gilts actively immunized against adrostenedione. J. Anim. Sci., v.66, p.3131-3143, 1988

MORÉS, N.; SOBESTIANSKY, J.; WENTZ, I. et al. Manejo do leitão do nascimento até o abate. In: SOBESTIANSKY, J.; WENTZ, I.; SILVEIRA, P.R.S. et al. (Eds.). Suinocultura Intensiva. Concórdia: EMBRAPA - CNPSA, 1998. p.135162.

NECHVATALOVA, K.; KUDLACKOVA, H., LEVA, L. et al. Transfer of humoral and cell-mediated immunity via colostrum in pigs. Vet. Immunol. Immunopathol., v.142, p.95100, 2011.
PIETERS, M.; BANDRICK, M.; PIJOAN, C. et al. The effect of cross-fostering on the transfer of Mycoplasma hyopneumoniae maternal immunity from the sow to the offspring. Clin. Vac. Immunol., v.15, p.540-543, 2008.

ROBERT, S.; MARTINEAU, G.P. Effects of repeated crossfostering on preweaning behavior and growth performance of piglets and on maternal behavior of sows. J. Anim. Sci., v.79, p.88-93, 2001

ROOKE, J.A.; CARRANCA, C.; BLAND, I.M. et al. Relationships between passive absorption of immunoglobulin $\mathrm{G}$ by the piglet and plasma concentrations of immunoglobulin G at weaning. Livest. Prod. Sci., v.81, p.223-234, 2003.

SALMON, H. The mammary gland and neonate mucosal immunity. Vet. Immunol. Immunopathol., v.72, p.143-155, 1999

SMITH, M.W.; JARVIS, L.G. Growth and cell replacement in the new-born pig intestine. Proc. R. Soc. London, v.203, p.69-89, 1978.

STOKES, C.; BOURNE, J.F. Mucosal immunity. In: HALLIWELL, R.E.W.; GORMAN, N.T. (Eds.). Veterinary Clinical Immunology. Philadelphia: W B Saunders, 1989. p.178-181.

STRAW, B.E.; BURGI, E.J.; DEWEY, C.E. et al. Effects of extensive crossfostering on performance of pigs on a farm. $J$. Am. Vet. Med. Assoc., v.212, p.855-856, 1998.

TUBOLY, S.; BERNÁTH, S.; GLÁVITS, R. et al. Intestinal absorption of colostral lymphoid cells in newborn piglets. Vet. Immunol. Immunopathol., v.20, p.75-85, 1988.

WAGSTROM, E.A.; YOON, K.; ZIMMERMAN, J.J. Immune components in porcine mammary secretions. Viral Immunol., v.13, p.383-397, 2000.

WATTANAKUL, W.; EDWARDS, S.A.; STEWART, A.H. et al. Effect of familiarity with the environment on the behaviour and performance response of sows and piglets to grouping during lactation. Appl. Anim. Behav. Sci., v.61, p.25-39, 1998.

WATTANAPHANSAK, S.; LUENGYOSLUECHAKUL, S.; LARRIESTRA, A. et al. The impact of cross-fostering on swine production. Thai. J. Vet. Med., v.32, suppl., p.101-106 2002

WERHAHN, E.; KLOBASA, F.; BUTLER, J.E. Investigation of some factors which influence the absorption of IgG by the neonatal piglet. Vet. Immunol. Immunopathol., v.2, p.35-51, 1981.

WILLIAMS, P.P. Immunomodulating effects of intestinal absorbed maternal colostral leukocytes by neonatal pigs. Can. J. Vet. Res., v.57, p.1-8, 1993. 